Check for updates

Cite this: Chem. Sci., 2018, 9, 6411

๑ All publication charges for this article have been paid for by the Royal Society of Chemistry

Received 14th May 2018

Accepted 28th June 2018

DOI: $10.1039 / \mathrm{c} 8 \mathrm{sc} 02126 \mathrm{k}$

rsc.li/chemical-science

\section{Ring-opening hydroarylation of monosubstituted cyclopropanes enabled by hexafluoroisopropanol $\uparrow$}

\author{
Edward Richmond, ${ }^{a}$ Jing Yi, ${ }^{a}$ Vuk D. Vuković, ${ }^{a}$ Fatima Sajadi, (DD ${ }^{b}$ \\ Christopher N. Rowley (iD *b and Joseph Moran (iD *a
}

\begin{abstract}
Ring-opening hydroarylation of cyclopropanes is typically limited to substrates bearing a donor-acceptor motif. Here, the transformation is achieved for monosubstituted cyclopropanes by using catalytic Brønsted acid in hexafluoroisopropanol (HFIP) solvent, constituting a rare example where such cyclopropanes engage in intermolecular $\mathrm{C}-\mathrm{C}$ bond formation. Branched products are obtained when electron-rich arylcyclopropanes react with a broad scope of arene nucleophiles in accord with a simple $\mathrm{S}_{\mathrm{N}} 1$-type ringopening mechanism. In contrast, linear products are obtained when cyclopropylketones react with electron-rich arene nucleophiles. In the latter case, mechanistic experiments and DFT-calculations support a homo-conjugate addition pathway.
\end{abstract}

\section{Introduction}

Cyclopropanes are readily accessed substrates whose strainrelease ring opening gives rise to highly functionalized products. ${ }^{1}$ The ring-opening hydroarylation of cyclopropanes installs an aryl moiety and a hydrogen atom in a 1,3-relationship. Thus far, it has mostly been described for so-called donor-acceptor cyclopropanes, a class of cyclopropanes that are highly tractable synthetic precursors due to the presence of electron-donating and electron-withdrawing groups arranged in a 1,2-relationship. ${ }^{2,3}$ Intermolecular ring-opening hydroarylation can also occur in cyclopropanes bearing two geminal acceptor groups, but only for indoles under ultra-high pressure (13 $000 \mathrm{~atm}$ ) conditions., ${ }^{\mathbf{4} 5}$ Catalytic ring-opening hydroarylation of monosubstituted cyclopropanes has yet to be reported. Generally speaking, the reactivity of monosubstituted cyclopropanes is much less developed than for donor-acceptor cyclopropanes. Existing ring-opening reactions include oxidative addition into $\mathrm{C}-\mathrm{C}$ bonds with transition metals, ${ }^{6-8}$ oxidative 1,3 -difunctionalization, ${ }^{9}$ frustrated Lewis pairs, ${ }^{\mathbf{1 0 1 1}}$ or addition of strong nucleophiles ${ }^{\mathbf{1 2 - 1 4}}$ and mineral acids. ${ }^{15}$ One-pot iodination/ alkylation procedures are also known. ${ }^{16}$ Our laboratory has begun to exploit the catalytically active aggregates formed between Brønsted acids and solvents such as hexafluoroisopropanol (HFIP) to enable challenging transformations. ${ }^{\mathbf{1 7}, 18}$ Herein, we report Brønsted acid catalyzed

${ }^{a}$ University of Strasbourg, CNRS, ISIS UMR 7006, 67000 Strasbourg, France. E-mail: moran@unistra.fr

${ }^{b}$ Memorial University of Newfoundland, 283 Prince Philip Drive, St. John's, NL, Canada, A1B3X7.E-mail: crowley@mun.ca

$\dagger$ Electronic supplementary information (ESI) available: Optimization data, experimental procedures, characterization of new compounds, computational methods and spectral data (PDF). See DOI: 10.1039/c8sc02126k arylative ring-opening of mono-substituted cyclopropanes in HFIP (Scheme 1, this work). Mechanistic experiments and DFT calculations indicate that, depending on cyclopropane substitution, two differing mechanistic pathways appear to be operative. Cyclopropanes bearing an aryl group furnish branched products and proceed through a carbocation intermediate, whereas cyclopropanes bearing a carbonyl group lead to linear products and react via a homo-conjugate addition pathway.

\section{Results and discussion}

\section{Synthetic studies}

Initial investigations began with the optimization of the reaction between commercial cyclopropyl phenyl ketone 1a and

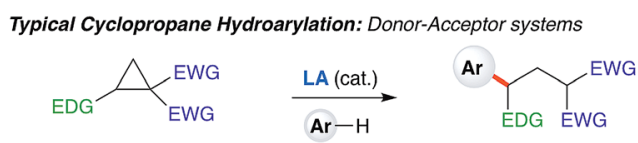

- cyclopropane polarisation through synergistic EDG/EWG combination This Work: Unified catalytic hydroarylation of non-DA cyclopropanes

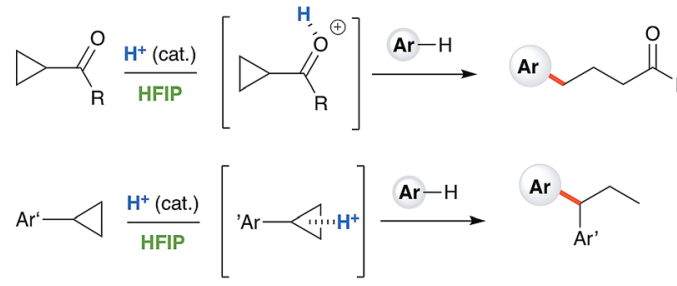

Scheme 1 Typical hydroarylation reactivity of cyclopropanes under Lewis acid catalysis using donor-acceptor substrates. This work: unified, HFIP-assisted, Brønsted acid-catalyzed cyclopropane hydroarylation. 
1,3,5-trimethoxybenzene. A screen of temperatures, acids, and solvents rapidly revealed that the combination of triflic acid (TfOH) catalyst in HFIP promoted smooth reactivity to the desired ring-opened adduct in near quantitative conversion and $67 \%$ isolated yield (Scheme 2, 2a). Application of these optimized reaction conditions to a series of ketone-bearing cyclopropanes $^{19}$ gave access to a range of $\gamma$-arylated ketone products in good to excellent yields. The aryl ketone was replaced with a methyl ketone with almost no impact on reactivity (2b), and a series of cyclopropyl aryl ketones bearing a variety of substituents $(\mathbf{2 d - j})$ was arylatively ring-opened in $67-98 \%$ yield. In this series, variation of the nucleophile revealed a range of electronrich arenes was well tolerated by the reaction system (entries $2 \mathbf{c}-$ e and $\mathbf{2 j}$ ), provided that a 1,3-methoxy motif was present in all cases. Nucleophiles lacking this 1,3-pattern, even 1,2,3- and 1,2,4-trimethoxybenzene, were found to be ineffective in this reaction, as were 1,4-dimethoxybenzene, indole derivatives and cyclopropanes bearing nitrile groups. ${ }^{20}$ The optimal reaction conditions also proved applicable to the arylative ring-opening reaction of cyclopropanes bearing two ester groups (Scheme 3, entries $2 \mathbf{k}-\mathbf{n}$ ), with almost no impact on the reaction efficiency. However, a substrate bearing a single ester group proved recalcitrant, providing only poor yields of the $\gamma$-arylation product (2o). With conditions established for the preparation of linear, $\gamma$-arylated carbonyl derivatives, we next elected to probe simple aryl-cyclopropanes as reaction partners in this catalytic protocol. To the best of our knowledge, such substrates have yet to be engaged in catalytic ring-opening reactions with nucleophiles other than thiols ${ }^{21}$ and a single example of a FriedelCrafts reaction..$^{22}$

Given the polarity reversal of such substrates compared to their carbonyl-bearing counterparts, opposing reactivity to yield the branched ring-opening product was expected. Indeed,

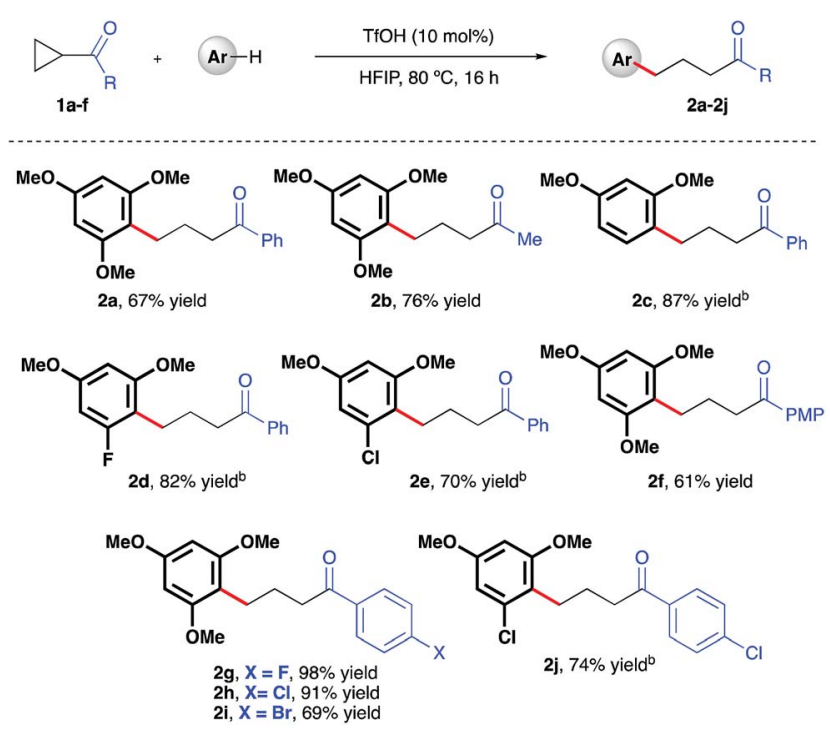

Scheme $2 \mathrm{TfOH}$-catalyzed, arylative ring-opening reactions of ketobearing cyclopropanes. ${ }^{a}$ Yields of isolated products after column chromatography over silica. ${ }^{b}$ Combined yield of regioisomeric products - see ESI† for further details.
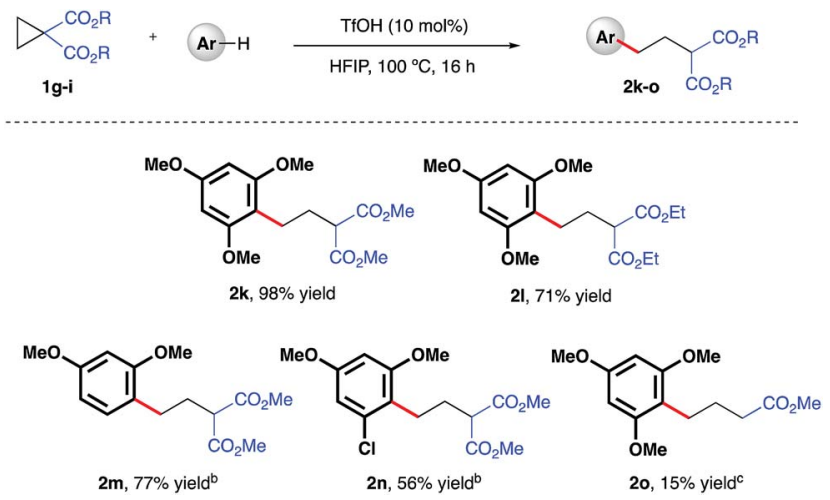

Scheme $3 \mathrm{TfOH}$-catalyzed, arylative ring-opening reactions of esterbearing cyclopropanes. ${ }^{a}$ Yields of isolated products after column chromatography over silica. ${ }^{\mathrm{b}} \mathrm{C}$ combined yield of regioisomeric products - see ESI† for further details. ${ }^{\mathrm{C}}$ Reaction heated at $100{ }^{\circ} \mathrm{C}$ in 1,2 dichloroethane.

reaction of cyclopropylbenzene with 1,2,4-trimethoxybenzene yielded the desired, branched product in $79 \%$ yield (Scheme 4 , 3a). A survey of the reaction scope with cyclopropylbenzene revealed a wider range of nucleophiles was tolerated in this reaction system (entries $\mathbf{3 b} \mathbf{b}-\mathbf{e}, \mathbf{k}, \mathbf{l}$ ), including less electron-rich arenes such as anisole (3e). Additionally, it was found that almost all of these reactions proceeded efficiently at room temperature. Variation of the aryl moiety of the cyclopropane proved unproblematic with electron-rich ( $3 \mathbf{f}$ and $\mathbf{3 g}$ ), electron-

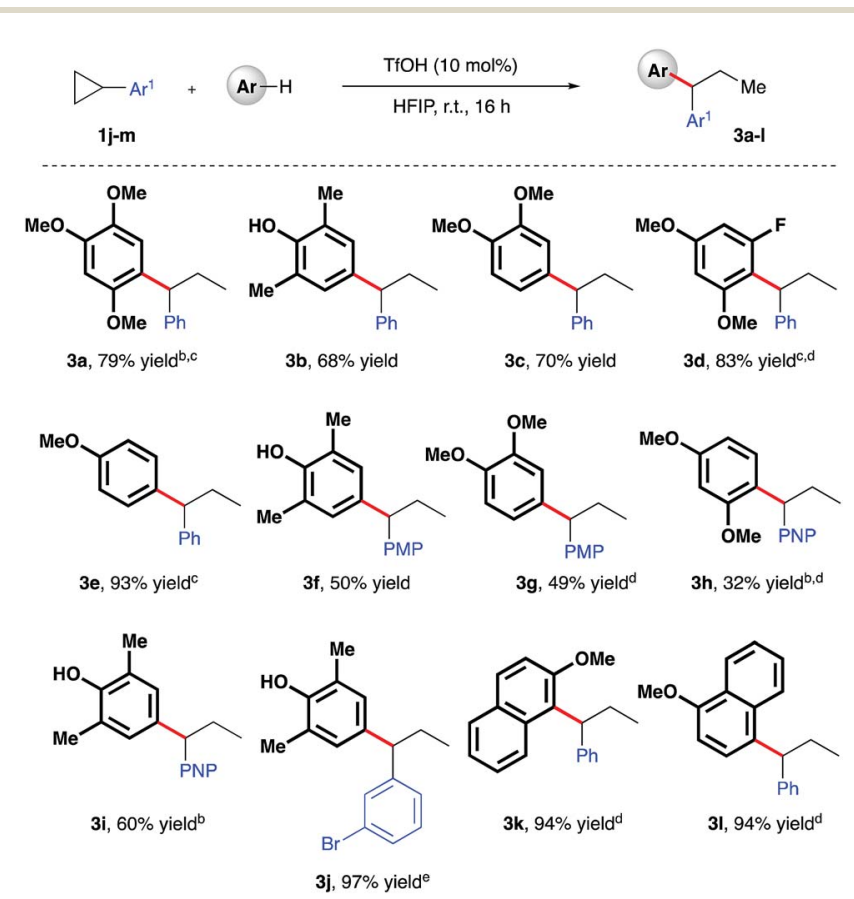

Scheme $4 \mathrm{TfOH}$-catalyzed, arylative ring-opening reactions of arylcyclopropanes. ${ }^{a}$ Yields of isolated products after column chromatography over silica. ${ }^{\mathrm{b}}$ Reaction heated at $80{ }^{\circ} \mathrm{C}$. ${ }^{\mathrm{C}} \mathrm{NMR}$ yield. ${ }^{\mathrm{d} C}$ Combined yield of regioisomeric products - see ESI† for further details. ${ }^{~} 1.1$ equiv. of nucleophile was used. PMP $=4$-methoxyphenyl-. $\mathrm{PNP}=4$-nitrophenyl- 
deficient (3h and $\mathbf{i}$ ) and halogenated ring systems (3j) all well tolerated. The catalytic reaction system was also successfully extended to the activation of benzylic cyclopropanes, in particular those bearing electron-deficient aryl rings (Scheme 5). In reaction with mesitylene, both pentafluorophenyl- and 4-nitrophenyl derivatives delivered methyl-substituted bis-aryls $3 \mathbf{m}$ and 3n respectively, presumably via Brønsted acid-mediated ring opening, followed by a 1,2-hydride shift to give the least inductively destabilized carbocation prior to nucleophilic capture by mesitylene. ${ }^{23}$

\section{Mechanistic \& computational studies}

In situ ${ }^{1} \mathrm{H}$ NMR titration studies of various reaction components in HFIP with TfOH were carried out in order to better rationalize the observed reactivity trends. Addition of $10 \mathrm{~mol} \% \mathrm{TfOH}$ to cyclopropylbenzene in HFIP in the absence of any nucleophile gave a highly exothermic reaction and an intense orange colour, with ${ }^{1} \mathrm{H}$ NMR analysis suggesting decomposition of starting material. This is in accord with prior literature on the reaction of similar cyclopropanes with mineral acids, in which a direct protonation yields an intermediate carbocation followed by collapse of the resulting ion pair. These observations, in combination with the wide nucleophile scope tolerated by such substrates, suggest that aryl cyclopropanes ring-open in the presence of $\mathrm{TfOH}$ and react via an $\mathrm{S}_{\mathrm{N}} 1$-type mechanistic pathway (Scheme 6). In contrast, initial in situ ${ }^{1} \mathrm{H}$ NMR experiments with cyclopropyl ketones suggest no spontaneous reactivity with TfOH in the absence of nucleophile. Rather, addition of $\mathrm{TfOH}$ to a $1: 1$ mixture of cyclopropyl phenyl ketone and 1,3,5-trimethoxybenzene revealed a complete preference for protonation of the latter. Titration of a solution of the 1,3,5trimethoxybenzene (1,3,5-TMB) nucleophile in HFIP with TfOH revealed that 1,3,5-TMB is rapidly and completely protonated to yield a dearomatized cationic diene (Fig. 1). ${ }^{24}$ At room temperature, a 1 : 1 mixture of cyclopropyl phenyl ketone and 1,3,5TMB shows complete protonation of the latter upon titration of TfOH. ${ }^{25}$ While an intriguing observation, thus far it has not been possible to establish whether this protonated nucleophile plays a more intimate role than simply being a 'resting state' for the catalyst. Additionally, this dearomatizing protonation is not observed in other solvents, suggesting that HFIP plays a more intimate role in the reaction beyond that of a bulk solvent. ${ }^{18 d}$
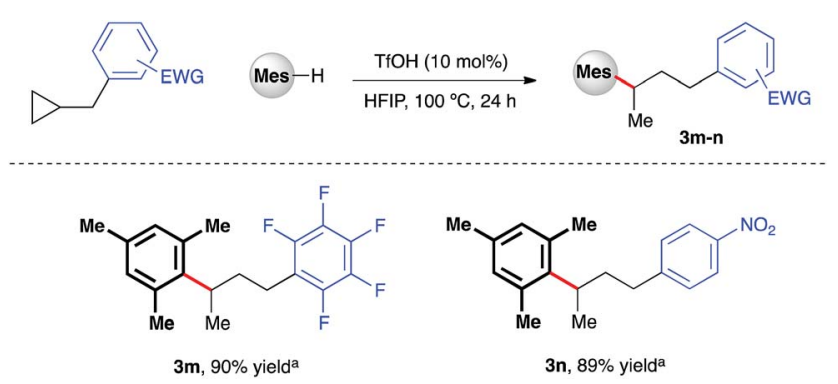

Scheme $5 \mathrm{TfOH}$-catalyzed arylative ring-opening of benzylic cyclopropanes. ${ }^{a}$ Yields of isolated products after column chromatography over silica. Mes = mesityl.
Mechanistic proposal for aryl-cyclopropanes

- $\mathrm{S}_{\mathrm{N}} 1$-type cyclopropane ring-opening.

- Acid-induced decomposition in the absence of nucleophile.

- Wide nucleophile scope.

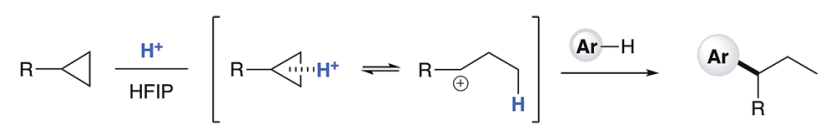

Scheme 6 Proposed $S_{N} 1$-type nucleophilic ring opening of arylcyclopropanes.

Thus, a tentative mechanistic scenario can be proposed where TfOH in HFIP initially enables protonation of 1,3,5-TMB (Scheme 7). Protonated TMB 4 can subsequently act as a reversible proton-reservoir ${ }^{26}$ to promote a homo-conjugate addition typical of donor-acceptor cyclopropanes.

To evaluate this hypothesis, this reaction system was probed via density functional theory calculations ( $\omega$ B97X-D/ def2-TZVP). A plausible mechanism was identified for the proposed Brønsted-acid-catalyzed homo-conjugate (Fig. 2). The ketone oxygen was predicted to be moderately basic for most cyclopropyl ketones, allowing it to be protonated by strong acids like TfOH. The protonated cyclopropyl ketone is activated for reaction with the arene, due to its partial enol character. This protonated cyclopropyl is then intercepted by the arene to form an arenium intermediate, which is the ratelimiting step. Deprotonation of the arenium intermediate yields an enol, which then tautomerizes to the ketone product. The calculated free energy profiles are generally consistent with the observed reactivity. Cyclopropyl methyl ester 1i (green line) did not react with 1,3,5-trimethoxybenzene, which is consistent with the calculations that show the barrier to this reaction is $9.7 \mathrm{kcal} \mathrm{mol}^{-1}$ higher than for the cyclopropyl dimethyl ester $\mathbf{1 g}$ (blue line). The calculated barrier for cyclopropyl dimethyl ester addition is only $1.2 \mathrm{kcal} \mathrm{mol}^{-1}$ higher than for the cyclopropyl methyl ketone 1b (black line), consistent with the high yields for these reactions. Likewise, the calculated activation energies for

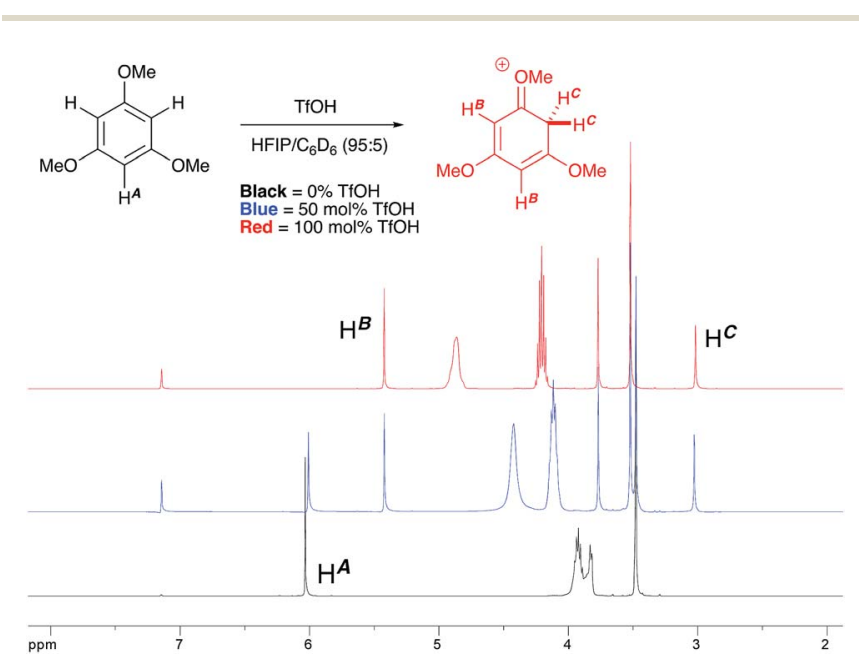

Fig. $1{ }^{1} \mathrm{H}$ NMR titration of 1,3,5-TMB with TfOH in HFIP leading to the observation of a dearomatized diene intermediate. 


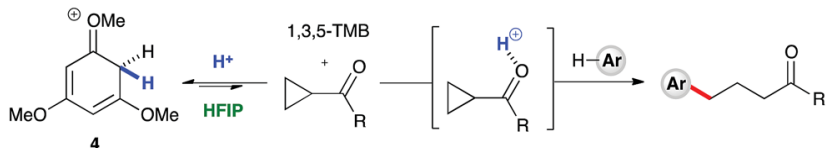

Scheme 7 A plausible mechanistic scenario: Brønsted acid catalyzed homo-conjugate addition.

addition of 1,2-, 1,2,3- and 1,2,4- methoxy-substituted arenes are significantly higher than for the reaction with 1,3,5trimethoxybenzene. ${ }^{25}$

To test the findings of the DFT-investigations experimentally, a series of reactions between 1,3,5-trimethoxybenzene and various cyclopropyl aryl ketones was performed and monitored by ${ }^{1} \mathrm{H}$ NMR spectroscopy over time. In an initial survey of cyclopropyl methyl- 1b, cyclopropyl phenyl- 1a, and cyclopropyl 4-methoxyphenyl-1c ketones, relative rates in agreement with the computed transition state energies were observed with cyclopropyl methyl ketone exhibiting a significantly faster rate of arylation (Fig. 3). A further comparison of the initial reaction rates of para- substituted aryl cyclopropanes (4-Me, 4-MeO, 4-F and $4-\mathrm{Cl}$ ), relative to that of the reaction of the parent cyclopropyl phenyl ketone, allowed a Hammett plot to be constructed for this reaction by plotting relative reaction rates $v s$. Hammett substituent parameter (sigma) (Fig. 4). Examination of the resulting plot reveals a strong linear relationship for most data, with a negative slope; an observation in agreement with the generation of positive charge on the substrate in the transition state. The magnitude of this slope is also strongly suggestive of an $\mathrm{S}_{\mathrm{N}}$ 2-like mechanism, i.e. homo-conjugate addition rather than a discrete carbocationic intermediate. Whilst most
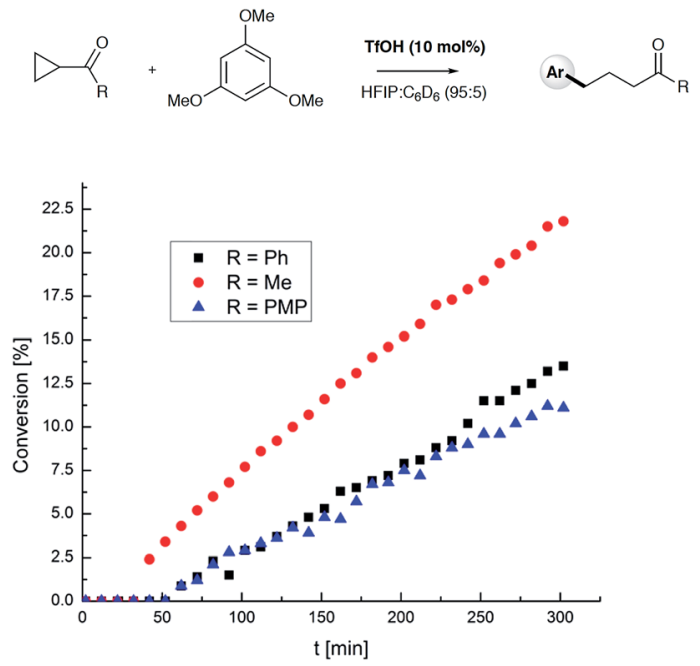

Fig. 3 Comparison of relative reaction rates for cyclopropyl phenyl ketone 1a (black squares), cyclopropyl methyl ketone $1 \mathrm{~b}$ (red circles), and cyclopropyl 4-methoxyphenyl ketone 1c (blue triangles) in reaction with 1,3,5-TMB. Reactions were monitored by ${ }^{1} \mathrm{H}$ NMR spectroscopy at $65^{\circ} \mathrm{C}$ and conversion (\%) is plotted vs. time (min).

inductively-stabilising substituents follow the expected trend and fall nicely on the observed line-of-best-fit, the data-point obtained for the reaction of the 4-methoxyphenyl cyclopropane ketone is a notable outlier. This observation can be rationalized from the computational data, which predicts the protonated form of this ketone to be exceptionally stable, so its rate of reaction is slowest if the activation energies are calculated relative to a protonated-ketone resting state. Taken together, this combined experimental and computational

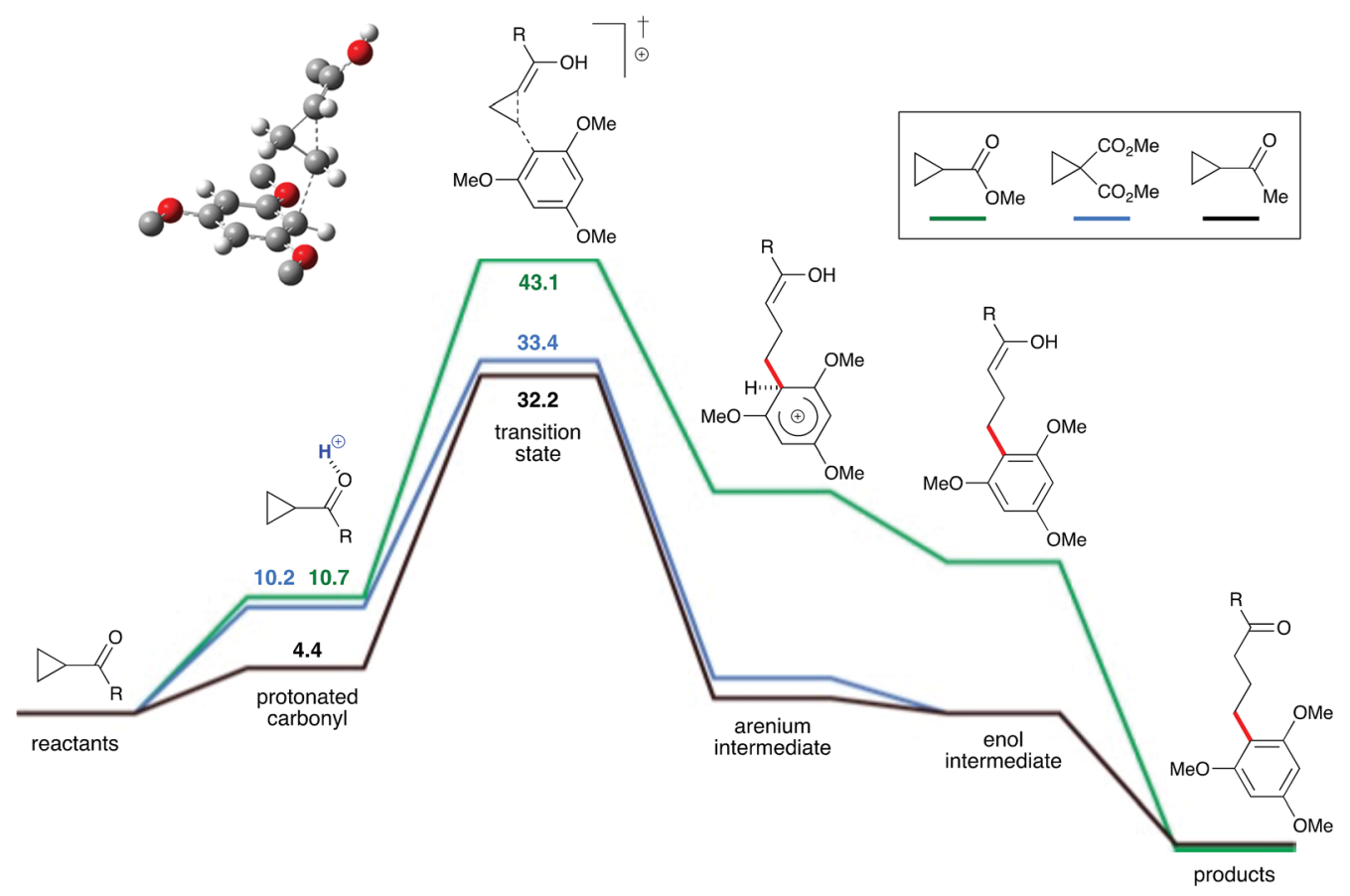

Fig. 2 DFT-calculated reaction profiles for the addition of cyclopropyl ketones or esters to arenes. Energy values in $\mathrm{kcal}^{\mathrm{mol}}{ }^{-1}$. 

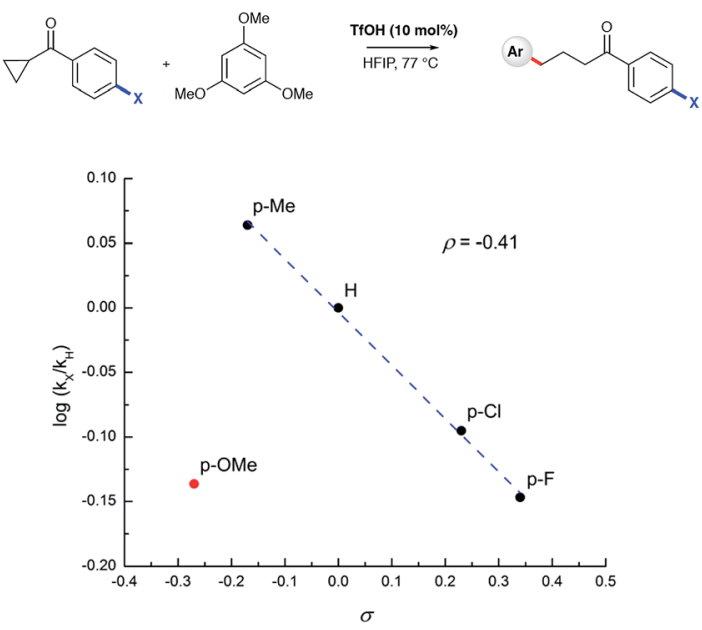

Fig. 4 Hammett plot of $\log \left(k_{X} / k_{H}\right)$ vs. sigma value for the depicted reaction. Initial rates were determined by plotting [product] vs. time as determined by ${ }^{1} \mathrm{H}$ NMR spectroscopy.

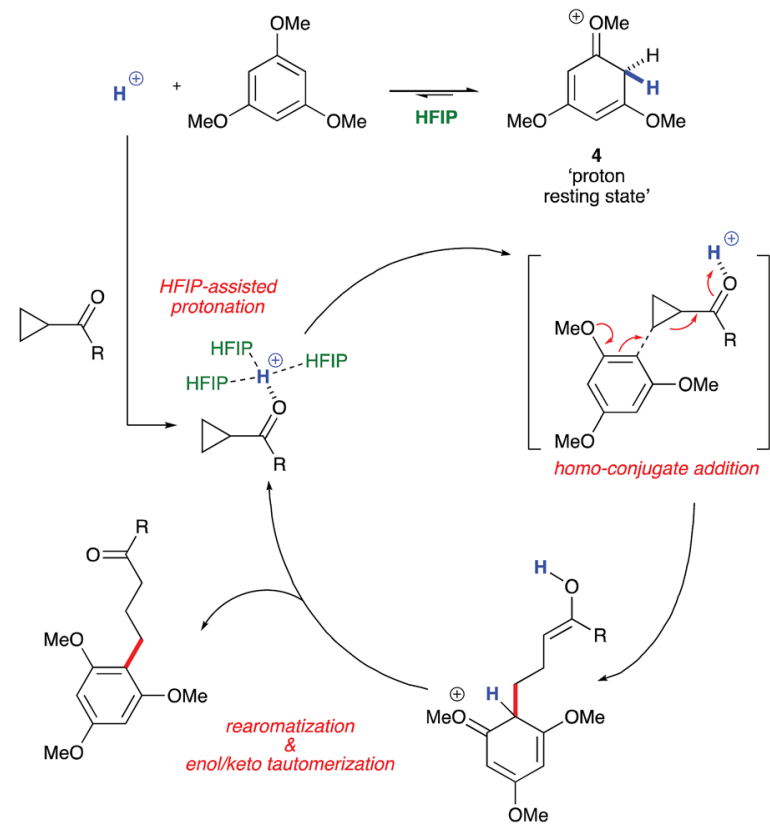

Scheme 8 A proposed homo-conjugate addition mechanistic pathway consistent with combined experimental and computational data.

insight provide strong support for the proposed homoconjugate addition mechanism, whereby initial HFIP-assisted protonation of the cyclopropyl carbonyl group induces nucleophilic ring-opening via a homo-conjugate addition pathway, leading to the enol form of the observed linear product (Scheme 8).

\section{Conclusions}

In conclusion, a general catalytic system for the arylative ring opening of mono-substituted cyclopropanes has been described. Triflic acid in combination with hexafluoroisopropanol provides a superior Brønsted acid catalyst system, engaging weakly-polarized substrates in Friedel-Craftstype reactivity. The regioselectivity and operative mechanism varies depending on the cyclopropane substitution, with carbonyl-bearing cyclopropanes reacting via a homo-conjugate addition pathway. Computational and mechanistic investigations are congruent with these findings.

\section{Conflicts of interest}

There are no conflicts to declare.

\section{Acknowledgements}

This project has received funding from the European Research Council (ERC) under the European Union's Horizon 2020 research and innovation programme (grant agreement no. 639170) and by grants from LabEx "Chemistry of Complex Systems". V. D. V. thanks the French government for an MRT fellowship. We thank Dr Helmut Muenster of MasCom for his assistance with HRMS analysis. F. S. and C. N. R. thank NSERC of Canada for funding through the Discovery Grant program (Application 418505-2012). Computational resources were provided by Compute Canada (RAPI: djk-615-ab). F. S. thanks Dr Liqin Chen for a graduate scholarship.

\section{Notes and references}

1 H. N. C. Wong, M.-Y. Hon, C. W. Tse, Y.-C. Yip, J. Tanko and T. Hudlickym, Chem. Rev., 1989, 89, 165.

2 For comprehensive overviews of the broad chemistry of donor-acceptor cyclopropanes, see: (a) H.-U. Reissig and R. Zimmer, Chem. Rev., 2003, 103, 1151; (b) M. Yu and B. L. Pagenkopf, Tetrahedron, 2005, 61, 321; (c) T. F. Schneider, J. Kaschel and D. B. Werz, Angew. Chem., Int. Ed., 2014, 53, 5504.

3 For examples of catalytic arylative ring-opening of donoracceptor cyclopropanes, see: (a) S. J. Gharpure, M. K. Shukla and U. Vijayasree, Org. Lett., 2009, 11, 5466; (b) S. J. Gharpure, U. Vijayasree and S. Raja Bhushan Reddy, Org. Biomol. Chem., 2012, 10, 1735; (c) X. Jiang, Z. Lim and Y.-Y. Yeung, Tetrahedron Lett., 2013, 54, 1798; (d) R. Talukdar, A. Saha, D. P. Tiwari and M. K. Ghorai, Tetrahedron, 2016, 72, 613; (e) T. N. Nguyen, T. S. Nguyen and J. A. May, Org. Lett., 2016, 18, 3786; (f) T. Kaicharla, T. Roy, M. Thangaraj, R. G. Gonnade and A. T. Biju, Angew. Chem., Int. Ed., 2016, 55, 10061.

4 P. Harrington and M. A. Kerr, Tetrahedron Lett., 1997, 38, 5949.

5 An annulative cyclopropane arylation using superstoichiometric TfOH has been reported: G.-Q. Chen, X.-Y. Tang and M. Shi, Chem. Commun., 2012, 48, 2340.

6 For reviews, see: (a) L. Souillart and N. Cramer, Chem. Rev., 2015, 115, 9410; (b) G. Fumagalli, S. Stanton and J. F. Bower, Chem. Rev., 2017, 17, 9404. For a leading 
reference, see: (c) S. C. Bart and P. J. Chirik, J. Am. Chem. Soc., 2003, 125, 886.

7 (a) D. M. Roundhill, D. N. Lawson and G. Wilkinson, J. Chem. Soc. A, 1968, 845; (b) Y. Koga and K. Narasaka, Chem. Lett., 1999, 28, 705; (c) M. H. Shaw and J. F. Bower, Chem. Commun., 2016, 52, 10817.

8 (a) L. Liu and J. Montgomery, J. Am. Chem. Soc., 2006, 128, 5348; (b) L. Liu and J. Montgomery, Org. Lett., 2007, 9, 3885; (c) T. Tamaki, M. Ohashi and S. Ogoshi, Angew. Chem., Int. Ed., 2011, 50, 12607.

9 For a recent, transition-metal free oxidative 1,3difunctionalization of cyclopropanes, see: S. M. Banik, K. M. Mennie and E. N. Jacobsen, J. Am. Chem. Soc., 2017, 139, 9152.

10 J. G. Morton, M. A. Dureen and D. W. Stephan, Chem. Commun., 2010, 46, 8947.

11 Z.-Y. Zhang, Z.-Y. Liu, R.-T. Guo, Y.-Q. Zhao, X. Li and X.-C. Wang, Angew. Chem., Int. Ed., 2017, 56, 4028.

12 For a short review, see: S. Danishefsky, Acc. Chem. Res., 1978, $12,66$.

13 W. A. Bone and W. H. Perkin, J. Chem. Soc., Trans., 1895, 67, 108.

14 (a) W. E. Truce and L. B. Lindy, J. Org. Chem., 1961, 26, 1463; (b) A. B. Smith and R. B. Scarborough Jr, Tetrahedron Lett., 1978, 19, 1649; (c) R. K. Dieter and S. Pounds, J. Org. Chem., 1982, 47, 3174.

15 For HX-mediated transformations, see: $(a)$ W. H. Perkin and T. R. Marshall, J. Chem. Soc., Trans., 1891, 59, 853; (b) J. B. Lambert, J. J. Napoli, K. K. Johnson, K. N. Taba and B. S. Packard, J. Org. Chem., 1985, 50, 1291; (c) W. Xu, W. R. Dolbier Jr and J. Salazar, J. Org. Chem., 2008, 73, 3535. Additionally, an example of intramolecular bromocyclization has also been reported: $(d)$ C. Roesner and U. Hennecke, Org. Lett., 2015, 17, 3226.

$16 \mathrm{~A}$ stoichiometric $\mathrm{CeCl}_{3} \cdot 7 \mathrm{H}_{2} \mathrm{O} / \mathrm{LiI}$ promoted reaction between indoles and cyclopropyl ketones has also been reported: J. S. Yadav, B. V. S. Reddy, D. Chandrakanth and G. Satheesh, Tetrahedron Lett., 2007, 48, 8040.

17 (a) M. Dryzhakov, M. Hellal, E. Wolf, F. C. Falk and J. Moran, J. Am. Chem. Soc., 2015, 137, 9555; (b) M. Dryzhakov and J. Moran, ACS Catal., 2016, 6, 3670; (c) M. Dryzhakov, E. Richmond, G. Li and J. Moran, J. Fluorine Chem., 2017, 193, 45; (d) V. D. Vukovic, E. Richmond, E. Wolf and J. Moran, Angew. Chem., Int. Ed., 2017, 56, 3085; (e) E. Richmond, V. Vuković and J. Moran, Org. Lett., 2018, 20, 574.
18 For examples of other HFIP-enabled strong Brønsted acid catalyzed reactions, see: (a) A. Saito, M. Takayama, A. Yamazaki, J. Numaguchi and Y. Hanzama, Tetrahedron, 2007, 63, 4039; (b) H. F. Motiwala, M. Charaschanya, V. W. Day and J. Aubé, J. Org. Chem., 2016, 81, 1593; (c) X. Zeng, S. Liu and B. Xu, Org. Lett., 2016, 18, 4770; (d) W. Liu, H. Wang and C.-J. Li, Org. Lett., 2016, 18, 2184; (e) T. Kamitanaka, K. Morimoto, K. Tsuboshima, D. Koseki, H. Takamuro, T. Dohi and Y. Kita, Angew. Chem., Int. Ed., 2016, 55, 15535. For a more generał overview of HFIP, see: (f) O. Holloczki, A. Berkessel, J. Mars, M. Mezger, A. Wiebe, S. R. Waldvogel and B. Kirchner, ACS Catal., 2017, 7, 1846.

19 See $\mathrm{ESI} \dagger$ for structural details of all cyclopropane starting materials.

20 For further details of ineffective substrate combinations, see the ESI file. $\dagger$

21 Y. S. Shabarov, L. G. Saginova and S. V. Veselovskaya, Zh. Org. Khim., 1986, 22, 768.

22 A Friedel-Crafts product was also isolated in 12\% yield as a side product in: T. Ohwada, M. Kasuga and K. Shudo, J. Org. Chem., 1990, 55, 2717.

23 In support of this mechanistic hypothesis, benzylic substrates bearing electron-rich aryl rings were found to give mixtures of regioisomeric products. Further studies into the nucleophilic ring-opening of benzylic cyclopropanes are ongoing.

24 Such behaviour has previously been observed with 1,3,5TMB using superacids such as $\mathrm{HF}^{-\mathrm{SbF}_{5}}$ as solvent, see: (a) G. A. Olah and Y. K. Mo, J. Am. Chem. Soc., 1972, 94, 5341. It has also been observed in HFIP using laser flash photolysis, see: $(b)$ S. Steenken and R. A. McClelland, J. Am. Chem. Soc., 1990, 112, 9648; (c) N. Mathivanan, F. Cozens, R. A. McClelland and S. Steenken, J. Am. Chem. Soc., 1992, 114, 2198.

$25 \mathrm{See} \mathrm{ESI}_{\dagger} \dagger$ for further information and NMR spectra of these competitive titration studies. Additionally, ${ }^{13} \mathrm{C}$ and ${ }^{1} \mathrm{H}$ NMR titration studies of cyclopropyl methyl ketone and TfOH in HFIP in the absence of nucleophile revealed no spontaneous cyclopropane opening, but a strong downfield shift of both the keto-carbonyl and methyl ${ }^{13} \mathrm{C}$ signals was observed.

26 D. Hoefler, M. van Gemmeren, P. Wedemann, K. Kaupmees, I. Leito, M. Leutzsch, J. B. Lingnau and B. List, Angew. Chem., Int. Ed., 2017, 55, 1411. 